\title{
Solid electrochemical mass spectrometry (SEMS) for investigation of supported metal catalysts under high vacuum
}

\author{
Cyril Falgairette $\cdot$ Chun Xia $\cdot$ YongDan Li $\cdot$ \\ Wolfgang Harbich $\cdot$ Christos Comninellis
}

Received: 17 February 2010/ Accepted: 4 June 2010/Published online: 6 July 2010

(C) Springer Science+Business Media B.V. 2010

\begin{abstract}
A new experimental set-up, coupling electrochemistry and mass spectroscopic techniques, for the investigation of a solid electrochemical cell under high vacuum conditions (HV) is presented. Two configurations are realized allowing the investigation of both the electrochemical and electrocatalytical behavior of a thin $\mathrm{Pt}$ layer on yttria stabilized zirconia (YSZ). We can readily select the atmosphere down to $10^{-6} \mathrm{~Pa}$ partial pressure and determine the response of the system in less than $1 \mathrm{~s}$. Under HV conditions, YSZ appears electrochemically active and we have identified, in the cathodic potential domain, the reduction/oxidation process of zirconia and in the anodic domain, the platinum oxidation/reduction and the oxygen evolution reactions. In a catalytic active gas mixture, despite the Faradaic enhancement of the CO oxidation observed over Pt/YSZ during an anodic polarization, an intriguing sustainable enhanced Pt/YSZ catalyst activity is achieved after current interruption.
\end{abstract}

Keywords Mass spectrometry - Electrochemistry · HV $\cdot$ Permanent EPOC $\cdot$ Pt electrodes

C. Falgairette $(\bowtie) \cdot C$. Xia · C. Comninellis

Institute of Chemical Sciences and Engineering, Ecole

Polytechnique Fédérale de Lausanne, 1015 Lausanne,

Switzerland

e-mail: cyril.falgairette@epfl.ch

C. Xia $\cdot$ W. Harbich

Institute of Condensed Matter Physics, Ecole Polytechnique

Fédérale de Lausanne, 1015 Lausanne, Switzerland

C. Xia $\cdot \mathrm{Y} . \mathrm{Li}$

Tianjin Key Laboratory of Applied Catalysis Science and Technology and State Key Laboratory for Chemical Engineering, School of Chemical Engineering, Tianjin University, Tianjin 300072, China

\section{Introduction}

Electrochemical mechanisms like electrochemical promotion of catalysts (EPOC) or non-Faradaic modification of catalytic activity (NEMCA) are complex multistage mechanisms which have not been understood completely on the molecular level. Coupling electrochemistry to other analytical probe techniques represents a constant effort in the field of research as it allows to gain valuable information for the elucidation of these complex mechanisms. Surface analysis techniques, e.g. Auger electron spectroscopy (AES), X-ray photoelectron spectroscopy (XPS) $[1,2]$, scanning photoelectron spectroscopy (SPEM) [3-5], photoelectron emission microscopy (PEEM) [4-7], scanning tunneling microscopy (STM), are usually coupled to electrochemistry to investigate electrochemical deposition and adsorption at the electrode while spectroscopic techniques, e.g. infrared-spectroscopy (IR), gas chromatography (GC) [8, 9], mass spectrometry (MS) [8-11], are coupled to monitor (qualitatively and quantitatively) the products of an electrochemical reaction. More recently, the field of aqueous electrochemistry yielded important insight from the development of differential electrochemical mass spectrometry (DEMS) technique allowing the in situ detection of electrochemically formed products and intermediates $[12,13]$.

In the field of electrochemical promotion of catalysis (EPOC) several investigation devices are based on the above mentioned coupling of analytical techniques to electrochemistry. Most of them are performed under atmospheric pressure conditions by coupling a galvanostatic pulse to a sensitive but relatively slow gas phase separation method (typically gas chromatography with flame ionization detector, FID or thermal conductivity detector TCD) for the gas phase analysis. These techniques 
have allowed to propose an EPOC model based on backspillover ion promoters [8]. In order to obtain a clearer mechanistic picture of the phenomenon and demonstrate the EPOC mechanism proposed at atmospheric pressure, Imbihl et al. [3-7] proposed to investigate EPOC under ultra high vacuum (UHV) conditions. Surface analysis tools like PEEM and SPEM were combined with success to electrochemical methods allowing the authors to directly observe the migration of $\mathrm{O}^{2-}$ promoters at the catalyst surface during an anodic polarization. Few years later, Vayenas et al. [10,11] proposed an EPOC investigation of $\mathrm{CO}$ oxidation using labeled oxygen showing the co-existence of two kinds of oxygen species on Pt interfaced to YSZ by using adsorption and thermal desorption which confirmed the EPOC sacrificial promoter model suggested under atmospheric conditions. However, at atmospheric pressure, after prolonged anodic polarization, Jaccoud et al. [14-17] have recently reported an intriguing (electrochemical and electrocatalytical) behavior of the Pt/YSZ system which cannot be explained by the commonly accepted EPOC model.

In order to shed more light on these processes, we made an effort to build a new device to perform electrochemical measurements under HV conditions, while monitoring the electrochemically formed products. An electrochemical microreactor configuration under $\mathrm{HV}$ conditions is linked to a quadrupole mass spectrometer (QMS) to monitor the reaction products of a solid state electrochemical system. The high sensitivity and the fast response of the QMS analyzer show to be key parameters of this new device. We were able to isolate the contribution of the solid electrolyte in the electrochemical behavior of the Pt/YSZ interface. We find that the electrochemical promotion of $\mathrm{CO}$ oxidation is Faradaic but presents a persistent effect after current interruption similarly to the sustainable enhanced catalyst activity observed in case of Persistent Electrochemical promotion (Pers-EPOC).

\section{Experimental setup}

The setup consists of two key parts, the electrochemical reactor and the mass spectrometer placed in a HV chamber (Fig. 1) which will be described briefly below. All experiments are performed under $\mathrm{HV}$ conditions or at well defined partial pressures up to $10^{-3} \mathrm{~Pa}$.

The vacuum vessel housing the microreactor and the QMS has a volume of $10 \mathrm{~L}$. The base pressure of the vacuum system is maintained typically at $10^{-6} \mathrm{~Pa}$ by a pumping system composed of two turbomolecular pumps (Pfeiffer TMU 521, $520 \mathrm{~L} \mathrm{~s}^{-1}$ and Peiffer TMU 071P, $60 \mathrm{~L} \mathrm{~s}^{-1}$ ) connected to a rotary pump (Trivac D16B,
$16 \mathrm{~m}^{3} \mathrm{~h}^{-1}$ ). The total volume and the effective pumping speed of the system yields a time constant of $20 \mathrm{~ms}$.

The electrochemical reactor is fixed on a HV manipulator allowing 3 translational and two rotational degrees of freedom which permits easy alignment with respect to the QMS and gas dosers. The reactor is electrically and thermally isolated. The system is mounted on a copper block which can be heated by a custom made heating system consisting of an electrically isolated tungsten filament $(12 \mathrm{~V}, 50 \mathrm{~W})$. Radiation heating or electron bombardment $(500 \mathrm{~V}, 50 \mathrm{~mA})$ is used according to the temperature range selected. Liquid nitrogen cooling of the sample is also provided but not used in the experiments presented here. Temperatures are measured using $\mathrm{NiCr}$ thermocouples at different points on the sample (see Sect. 4 below).

The gases used as reactants $\left(\mathrm{O}_{2}\right.$ (46 purity) and $\mathrm{CO}(60$ purity) Carbagas certified) are introduced in the system via HV leak valves and capillary stainless steel gas lines. Total pressures are monitored by a cold cathode pressure gage and partial pressures by the QMS operated under static conditions (no differential pumping).

\subsection{Mass spectrometric equipment}

The mass spectrometric equipment consists of a commercial quadrupole residual gas analyzer (Pfeiffer, Prisma200). Effective gas separation and detection is achieved by placing the QMS in a custom built "sniffer" device composed of multi-cylindric stainless steel tubes $[18,19]$. The "sniffer", depicted in Fig. 2, aims to collect efficiently the gases desorbing from the sample surface. Its front opening ( $3.5 \mathrm{~mm}$ diameter) can be placed in the vicinity of the gas feed to be analyzed and its cone shape ensures the diffusion of non-collected molecules away from the electrochemical reactor, i.e. avoids gas back mixing.

The reactant gases are introduced by two gas capillary tubes built on both sides of the device as shown in Fig. 2 . For the single chamber type reactor configuration, the oxygen gas source is released in the main HV chamber in order to set a homogenous $p_{\mathrm{O}_{2}}$ partial pressure both in the anodic and cathodic chamber of the reactor (electrochemical investigation) (Fig. 1a). On the other hand, for the dual chamber type reactor configuration, reactant gases are directly transferred to the anodic and to the cathodic chambers by connecting the capillary tubes to the gas inlet of electrochemical cell with Teflon tubes avoiding gas loss into the HV main chamber (catalytic measurements) (Fig. 1b).

The volume of the detection chamber is differentially pumped by a $60 \mathrm{~L} \mathrm{~s}^{-1}$ turbomolecular pump to ensure a continuous evacuation of analyzed gases. However, because of the complex multi-section structure of the device, the effective pumping speed is reduced to $S=0.63 \mathrm{~L} \mathrm{~s}^{-1}$ 
Fig. 1 Scheme of the high vacuum experimental setup. a single chamber configuration, b dual chamber configuration
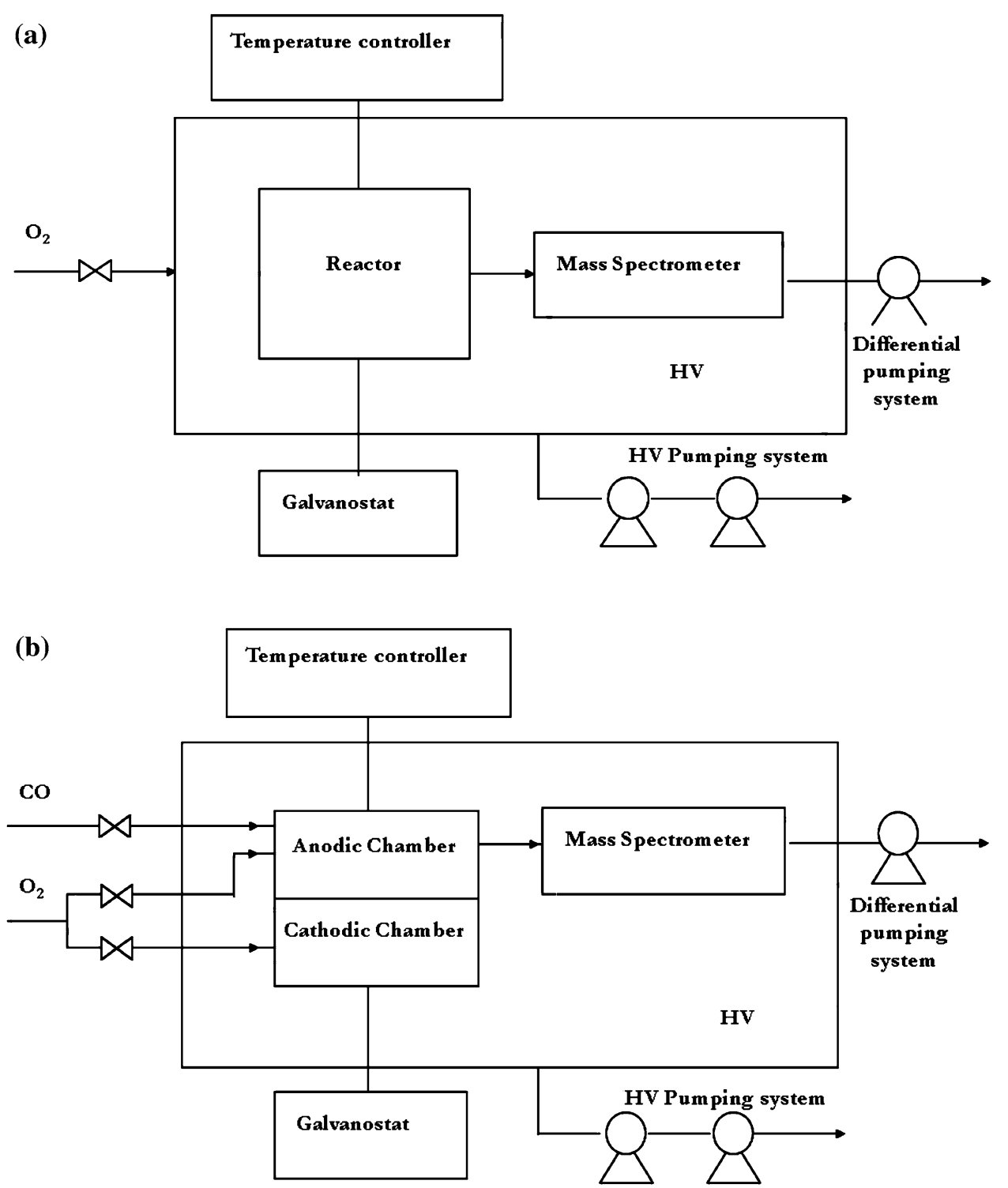

Fig. 2 Scheme of the sniffer. 1: main inox cylinder containing the QMS, 2: cone shape collector; 3: quadrupole mass spectrometer (QMS), 4: inlet gases capillary tubes, 5 : differential pumping

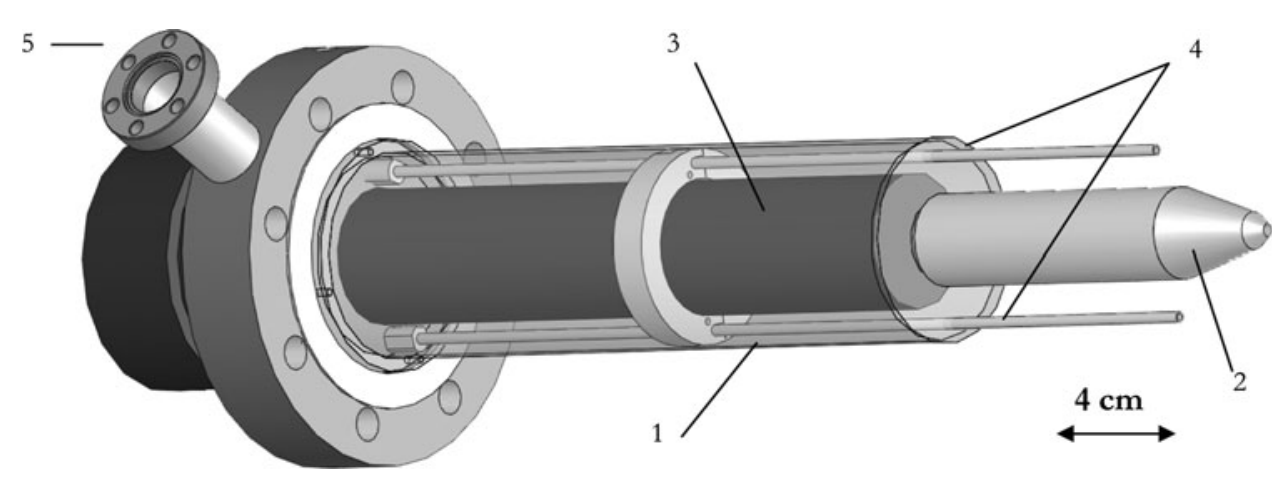

according to molecular flow theory [20] and to measurements. Considering the volume of the gas collector $\left(\mathrm{V}_{0}=0.38 \mathrm{~L}\right)$, the detection time constant is determined to be $0.6 \mathrm{~s}$.
2.2 Electrochemical reactors

Two types of reactors were designed, a single chamber type reactor (Fig. 3a) well suited for electrochemical 
Fig. 3 Scheme of the single chamber (a) and dual chamber electrochemical reactor $(\mathbf{b})$. 1: reference compartment; 2 : working compartment, 3 : sample 4: holes ensuring electrical and thermocouple connections, 5: holes ensuring free gas circulation 6: top hole facing the entrance of the sniffer (MS detection), 7: $\mathrm{CO}$ inlet gasline, 8: $\mathrm{O}_{2}$ inlet gasline, 9: sniffer gas collector

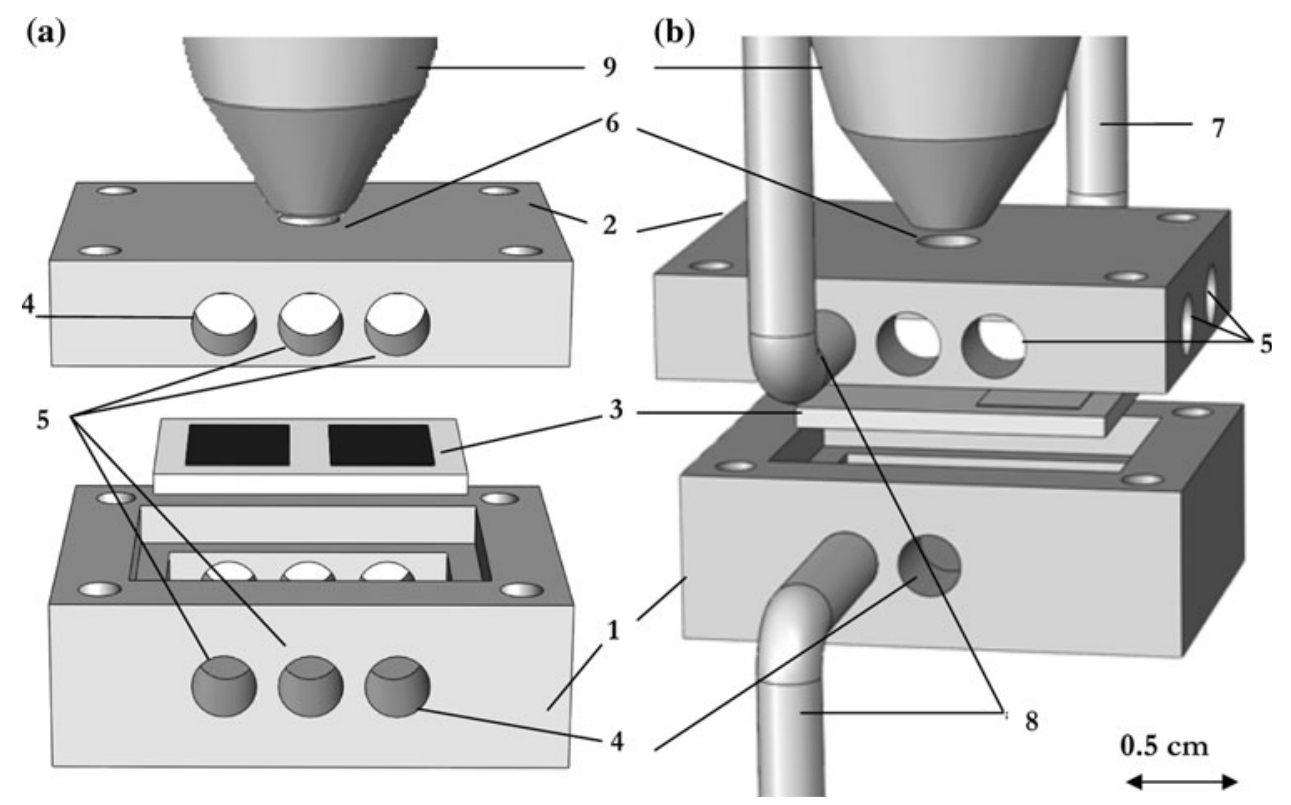

investigation of the Pt/YSZ system and a dual chamber type reactor (Fig. 3b) adapted to catalytic investigation (EPOC and P-EPOC).

\subsubsection{Single chamber type reactor}

The electrochemical reactor is composed of two copper pieces which act as a support for the sample and ensures electrical connections as well as thermal anchoring of the thermocouples (Fig. 3a). The sample is fixed in the middle of the electrochemical reactor by means of an inert ceramic paste (Feuerfestkitt, Firag AG), separating the whole support volume in a working compartment (containing WE and thermocouple, $V_{\text {working }}=0.7 \mathrm{~cm}^{3}$ ) and a reference compartment (containing $\mathrm{CE}$ and $\mathrm{RE}, V_{\text {reference }}=$ $\left.0.5 \mathrm{~cm}^{3}\right)$. Essential in this configuration however is free gas flow (ensured by the openings as depicted in Fig. 3a) which ensures a homogenous gas atmosphere on both sides of the sample which is basically identical to the vacuum chamber partial pressure distribution.

The gas analysis of the working compartment which probes the gases desorbed from the WE is performed via a $3 \mathrm{~mm}$ diameter hole placed on the top face of the reactor. Due to the open configuration only part of the desorbed gas is fed into the "sniffer". A quantitative analysis however is possible by determining the branching ratio of the gas flux (see Sect. 4 below).

The pumping speed of the reactor, determined by the gas flow theory at the openings, is estimated to be $1.15 \mathrm{~L} \mathrm{~s}^{-1}$. Considering the volume of the reactor, this results in a time constant of $1 \mathrm{~ms}$ which is much faster than the vacuum system and we can consider the reactor as operating in constant homogeneous pressure conditions.

\subsubsection{Dual chamber type reactor}

The design of the dual chamber type reactor is similar hardwarewise than the single chamber type reactor. However some important changes are made as shown in Fig. 3b. In this case the sample is sealed gas tight in the reactor with an inert ceramic paste (Feuerfestkitt, Firag AG), separating two independent volumes. The working compartment is efficiently pumped by seven openings ( $3 \mathrm{~mm}$ diameter holes) while the reference compartment is sealed. The feed of reactant gases is ensured by stainless steel inlet gas lines ( $2.8 \mathrm{~mm}$ diameter) connected to two openings of the working compartment $\left(\mathrm{O}_{2}\right.$ and $\left.\mathrm{CO}\right)$ and to one opening of the reference compartment $\left(\mathrm{O}_{2}\right)$. Temperature monitoring and gas analysis of the dual chamber type reactor is identical to the single chamber type reactor described above.

Due to the open construction we can estimate the time constant of the working compartment to be $0.8 \mathrm{~ms}$.

\subsection{Electrochemical cells}

Commercial YSZ 8\% mol pellet (Technox 802, Dynamic Ceramic) were used as substrate on which platinum electrodes were deposited by magnetron sputtering in $\mathrm{Ar}$ at room temperature. The magnetron operates in the direct current (dc) mode maintaining a discharge of $330 \mathrm{~V}$ at an argon pressure of $1 \mathrm{~Pa}$. Under these conditions, a $1 \mu \mathrm{m}$ thick Pt electrode was deposited with a deposition rate of $0.09 \mathrm{~nm} \mathrm{~s}^{-1}$ on the YSZ pellet, as determined by profilometric measurement (Alphastep, Model 500) of the film deposited on smooth silicon samples processed simultaneously. 
Electrochemical investigations (single chamber configuration) are conducted with a Pt/YSZ/Pt sample which means that counter and reference electrodes have been deposited with $\mathrm{Pt}$ on the reverse side of the pellet using the same sputtering procedure.

Catalytic measurements (dual chamber configuration) are performed over a Pt/YSZ/Au system. This is important to ensure the catalytic inertness of gold counter and reference electrodes which are deposited on the other side of the pellet by application of metalorganic paste (Gwent Electronic Materials-C70219R4) followed by calcination at $550{ }^{\circ} \mathrm{C}$. Both samples have been treated at $700{ }^{\circ} \mathrm{C}$ in $20 \mathrm{kPa} \mathrm{O}_{2}$ during $4 \mathrm{~h}$ in order to stabilize the platinum films [14].

The Pt working electrode size is $7 \times 5 \mathrm{~mm}$ giving a geometric surface of $0.35 \mathrm{~cm}^{2}$. The working and counter electrodes were located in a symmetrical face-to-face arrangement on the opposite side of the YSZ pellet. This geometry ensured a symmetrical current and potential distribution in the cell [21].

\section{Results and discussion}

\subsection{QMS calibration}

The online analysis of the gas composition is computed by measuring the response (ion current) for each gas with the quadrupole mass spectrometer. The ion current $\left(I_{X}\right)$ is directly proportional to the partial pressure of the analyzed gas in the sniffer volume $\left(p_{\mathrm{X}}^{\text {sniffer }}\right)$,

$I_{\mathrm{X}}=K_{\mathrm{X}} p_{\mathrm{X}}^{\text {sniffer }}$

where $K_{\mathrm{X}}$ is a constant containing all mass spectrometric conversion factors and the gas dependent ionization probability in $\mathrm{A} \mathrm{Pa}^{-1}$.

The QMS is absolutely calibrated comparing the ion current to the pressure reading of a Balzers CPG300 Cold cathode gauge. Stopping all differential pumping results in a homogenous gas pressure in the whole vacuum system. The ionic current, $I_{\mathrm{X}}$, and analyzed gas pressure, $p_{\mathrm{X}}^{\mathrm{HV}}$, in the HV chamber can then be written as:

$I_{\mathrm{X}}=K_{\mathrm{X}}^{0} p_{\mathrm{X}}^{\mathrm{HV}}$

where the constant $K_{\mathrm{X}}^{0}$ coefficient is similar to $K$ and contains all MS parameters under stationary conditions (Fig. 4, Table 1).

\subsection{SEMS calibration}

The polarization of the sample leads to electrochemical product formation of species which are eventually transferred into the gas phase. One of the main purposes of this

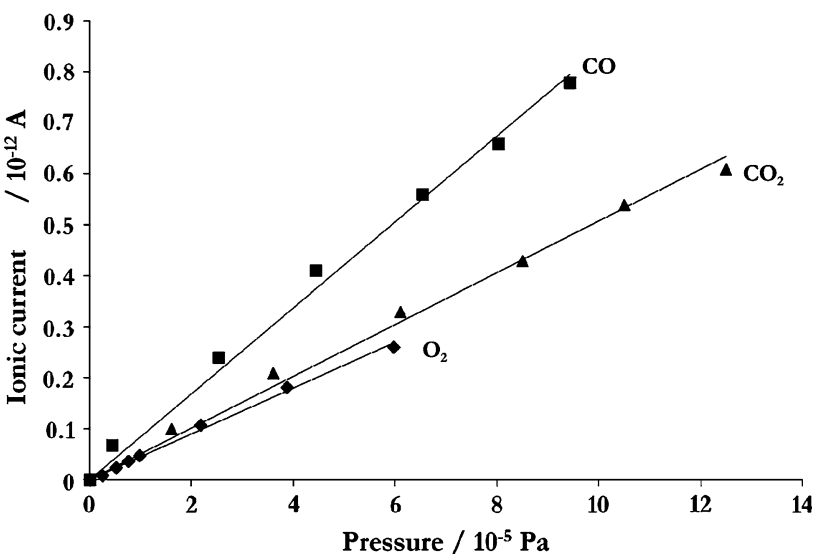

Fig. 4 Linear dependence of the HV chamber pressure to the measured ionic current intensity of the calibrating gas. (1) $\mathrm{O}_{2(\mathrm{~g})}(2)$ $\mathrm{CO}_{(\mathrm{g})}$ and (3) $\mathrm{CO}_{2(\mathrm{~g})}$. Calibration conditions

Table 1 Calibration coefficient $K_{\mathrm{X}}^{0}$ for $\mathrm{O}_{2(\mathrm{~g})}, \mathrm{CO}_{(\mathrm{g})}$ and $\mathrm{CO}_{2(\mathrm{~g})}$

\begin{tabular}{ll}
\hline$K_{\mathrm{O}_{2}}^{0}$ & $4.6 \times 10^{-8} \mathrm{~A} \mathrm{~Pa}^{-1}$ \\
$K_{\mathrm{CO}}^{0}$ & $8 \times 10^{-8} \mathrm{~A} \mathrm{~Pa}^{-1}$ \\
$K_{\mathrm{CO}_{2}}^{0}$ & $5 \times 10^{-8} \mathrm{~A} \mathrm{~Pa}^{-1}$ \\
\hline
\end{tabular}

experiment is to quantitatively analyze this product flow into the gas phase. The gas analysis of the working compartment is performed by means of the QMS through the top reactor hole which faces the "sniffer" entrance. In order to relate quantitatively the gas flow from the active electrode $J_{\mathrm{O}_{2}}^{\text {sniffer }}$ to the ion current measured in the QMS we use the oxygen evolution reaction in the Pt/YSZ system [13]. In the case of anodic polarization, $\mathrm{O}^{2-}$ ions migrate to the interface where they electrochemically react according to reaction 4 at the Pt/YSZ interface [14-16] and reaction 5 at the Triple Phase Boundary (TPB) [8, 14-16]:

$x \mathrm{O}_{(\mathrm{s})}^{2-}+\mathrm{Pt}_{(\mathrm{s})} \rightarrow \mathrm{PtO}_{\mathrm{x}(\mathrm{s})}+2 x e^{-}$

$2 \mathrm{O}_{(\mathrm{s})}^{2-} \rightarrow \mathrm{O}_{2(\mathrm{~g})}+4 e^{-}$

However, only $\mathrm{O}_{2(\mathrm{~g})}$ is released into the gas phase during this process, i.e. $\mathrm{O}_{2(\mathrm{~g})}$ is the only product formation which may be sampled by the MS. Reaction (4) dominates largely at high overpotential $[8,12]$ and $100 \%$ current efficiency can be assumed for the oxygen evolution reaction taking place at the TPB. The electrochemical oxygen flow produced by an anodic polarization of the working electrode is related to the Faradaic current flowing into the Pt/YSZ/Pt cell as follows:

$J_{\mathrm{O}_{2}}^{\text {sample }}=\frac{I_{\mathrm{f}}}{4 F}$

where $I_{\mathrm{f}}$ is the Faradaic current imposed to the cell, $J_{\mathrm{O}_{2}}^{\text {sample }}$ is the electrochemically formed oxygen flow and $F$ the Faraday constant. 
Nevertheless, only a fraction of the gas coming out of the working compartment goes in the "sniffer"

$J_{\mathrm{O}_{2}}^{\text {sniffer }}=N J_{\mathrm{O}_{2}}^{\text {sample }}$

where $J_{\mathrm{O}_{2}}^{\text {sniffer }}$ is the oxygen flow entering the sniffer and $N$ the transfer efficiency.

The oxygen pressure in the sniffer is related to $J_{\mathrm{O}_{2}}^{\text {sniffer }}$ by

$p_{\mathrm{O}_{2}}^{\text {sniffer }}=\frac{R T}{S} J_{\mathrm{O}_{2}}^{\text {sniffer }}$

where $R$ is the gas constant, $T$ the temperature and $S$ the pumping speed of the working compartment. This relates to the measured ion current

$I_{\mathrm{O}_{2}}=N K_{\mathrm{O}_{2}}^{0} \frac{R T}{S} J_{\mathrm{O}_{2}}^{\text {Sniffer }}$

and finally

$I_{\mathrm{O}_{2}}=N K_{\mathrm{O}_{2}}^{0} \frac{R T}{S} \frac{I_{\mathrm{f}}}{4 F}$

where $I_{\mathrm{O}_{2}}$ is the oxygen ion current which is measured by the QMS, $I_{\mathrm{f}}$ is the Faradaic current imposed to the cell and $K^{0}$ the MS calibration constant.

The linear relation between $I_{\mathrm{O}_{2}}$ and $I_{\mathrm{f}}$ is shown in Fig. 5 and allows the determination of $N$, which is estimated to be 0.098 for this setup.

A similar calibration is performed for the dual chamber type reactor, e.g. under background pressure of oxygen in both compartments $\left(p_{\mathrm{O}_{2}}=10^{-5} \mathrm{~Pa}\right)$. Doing so, the oxygen ion current recorded with the MS, $I_{\mathrm{O}_{2}}$, is related the Faradaic current imposed with the galvanostat, $I_{\mathrm{f}}$, to determine the transfer efficiency $N=0.069$ for the dual chamber type reactor configuration.

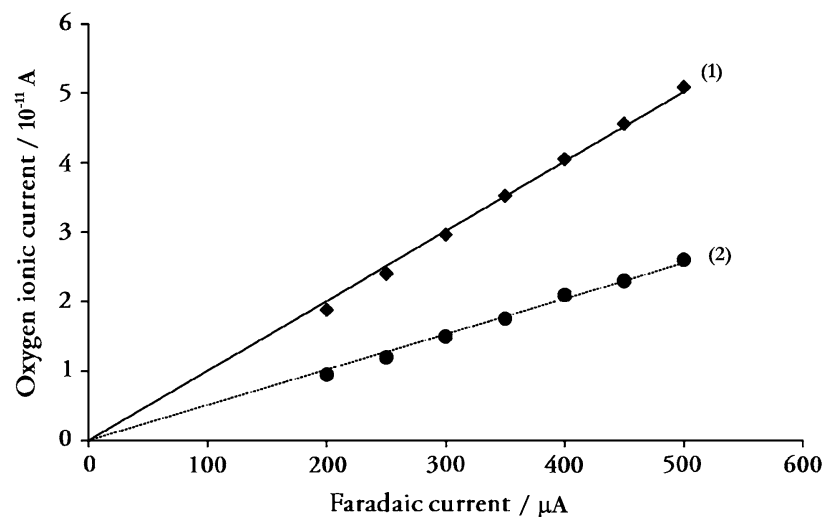

Fig. 5 Dependence of oxygen ionic current intensity measured to the applied Faradaic current. Application of the current is performed during $60 \mathrm{~s}$ under background oxygen partial pressure of $10^{-5} \mathrm{~Pa}$ at $T=400{ }^{\circ} \mathrm{C}$. Single chamber reactor (1), dual chamber reactor (2)

\subsection{Examples of application}

Single chamber type SEMS. The electrochemical investigation of the Pt/YSZ system is performed by cyclic voltammetry (CV-MS measurement) under $\mathrm{HV}$ in absence of oxygen (oxygen background pressure $p_{\mathrm{O}_{2}} \leq 10^{-5} \mathrm{~Pa}$ ) at $400{ }^{\circ} \mathrm{C}$ in the single chamber type configuration setup. The cyclic voltammograms (Fig. 6 left axis) and corresponding mass spectrometer (MS) results (Fig. 6 right axis) obtained by increasing the potential scan rate, $v$, from $10 \mathrm{mV} \mathrm{s}^{-1}$ up to $250 \mathrm{mV} \mathrm{s}^{-1}$ are presented in Fig. 6. In the anodic domain, the oxygen evolution reaction starts at $500 \mathrm{mV}$ (scan rate independent) leading to a dramatic increase of current on the voltammograms concomitant to strong oxygen release in the gas phase. In addition, the characteristic oxidation shoulder and reduction peak of the $\mathrm{Pt} / \mathrm{PtO}$ redox couple may be clearly seen in the anodic domain while an unexpected active couple $\left(\mathrm{Zr} / \mathrm{ZrO}_{2}\right)$ appears in the cathodic potential domain.

Dual chamber type SEMS. The electrocatalytic investigation of $\mathrm{CO}$ oxidation over $\mathrm{Pt} / \mathrm{YSZ}$ catalyst is performed by imposing a single anodic galvanostatic step under $\mathrm{HV}$ conditions in excess of $\mathrm{CO}\left(p_{\mathrm{O}_{2}}=10^{-5} \mathrm{~Pa}, p_{\mathrm{CO}}=\right.$ $\left.7 \times 10^{-3} \mathrm{~Pa}\right)$ at $400{ }^{\circ} \mathrm{C}$ in the dual chamber reactor type configuration setup. Figure 7 evidences the faradaic enhancement of $\mathrm{CO}_{2}$ formation ( $\rho=1.5$ and $\Lambda=0.1$ ) observed during the anodic polarization.

As previously mentioned, the detection efficiency of the electrochemically formed product is rather small $\left(N_{\text {single }}=\right.$ 0.093 and $N_{\text {dual }}=0.069$ ) but worth to notice that the small detection time constant of the system allowed to perform MS online sampling of oxygen production with a good resolution in time for cyclic voltammetric measurements with scan rates up to $200 \mathrm{mV} \mathrm{s}^{-1}$. This suggests that the

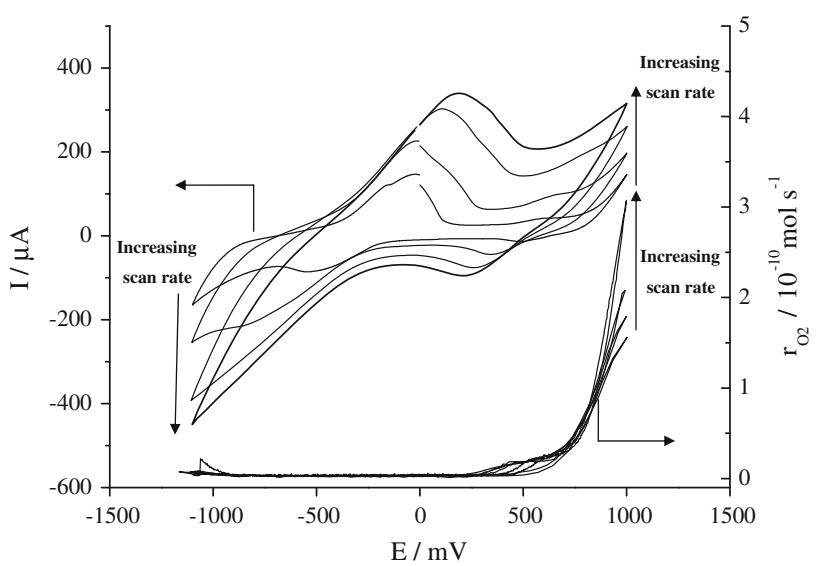

Fig. 6 Effect of scan rate on cyclic voltammogram of Pt/YSZ interface under $\mathrm{HV}, \mathrm{v}=10 \mathrm{mV} \mathrm{s}^{-1}, 20 \mathrm{mV} \mathrm{s}^{-1}, \quad 50 \mathrm{mV} \mathrm{s}^{-1}$, $100 \mathrm{mV} \mathrm{s}^{-1}, 150 \mathrm{mV} \mathrm{s}^{-1}, 200 \mathrm{mV} \mathrm{s}^{-1}$ and $250 \mathrm{mV} \mathrm{s}^{-1}$ (left axis) and corresponding MS results of $\mathrm{O}_{2}$ evolution (right axis). $p_{\mathrm{O}_{2}}=$ $10^{-5} \mathrm{~Pa}, T=400{ }^{\circ} \mathrm{C}$ 

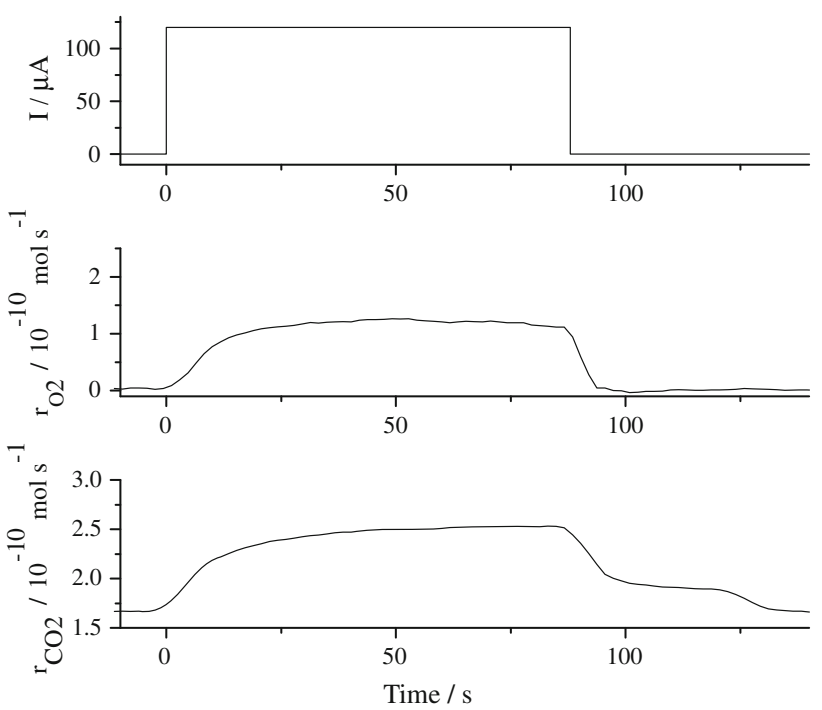

Fig. 7 Effect of galvanostatic polarization at $120 \mu \mathrm{A}$ during $90 \mathrm{~s}$ on the catalytic oxidation of $\mathrm{CO}$ over $\mathrm{Pt} / \mathrm{YSZ}$ catalyst under $\mathrm{HV}$, $p_{\mathrm{CO}}=7 \times 10^{-3} \mathrm{~Pa}, p_{\mathrm{O}_{2}}=10^{-5} \mathrm{~Pa}, T=400{ }^{\circ} \mathrm{C}$

sustainable enhancement of $\mathrm{CO}_{2}$ formation observed during $60 \mathrm{~s}$ after current interruption in Fig. 7 is related to the previously applied anodic current. Even if the polarization time involved in this example (100 s) is much more limited than the extended polarization times used by Comninellis et al. [14-17] during their investigation of P-EPOC of $\mathrm{Pt} / \mathrm{YSZ}$ catalyst under atmospheric pressure, the unexpected behavior observed herein, is proposed to be related to a similar process of oxygen storage by $\mathrm{PtO}_{\mathrm{x}}$ electrochemical formation. However this is far beyond the scope of this paper and a detailed SEMS investigation of $\mathrm{Pt} / \mathrm{YSZ}$ electrochemical behavior under HV conditions is given in the next article in this volume [22].

\section{Discussion}

The elaboration of a new probe accessory for the investigation of solid state electrochemical systems under HV condition leads to the development of two differential solid electrochemical mass spectrometry apparatus. The main characteristic of the investigation devices built herein are summarized in Table 2 which gives the relevant parameter of the different constituting parts of each configuration, i.e. vacuum system, heating system, mass spectrometric analysis, reactant gas supply and the electrochemical reactor.

The heating system was carefully designed in order to avoid any $\mathrm{O}^{2-}$ thermal migration in the YSZ electrolyte, i.e. to insure that in the single chamber reactor $\mathrm{OCV}=$ $0 \mathrm{~V}$. The use of a single filament placed in the vicinity of the working electrode, as commonly seen in most HV/TPD experimental setups [9-11], creates a large
Table 2 Main parameters and characteristics for each configuration

\begin{tabular}{|c|c|c|}
\hline & $\begin{array}{l}\text { Single chamber } \\
\text { configuration }\end{array}$ & $\begin{array}{l}\text { Dual chamber } \\
\text { configuration }\end{array}$ \\
\hline \multicolumn{3}{|l|}{ Vacuum system } \\
\hline Volume & $10 \mathrm{~L}$ & $10 \mathrm{~L}$ \\
\hline Pumping speed & $520 \mathrm{~L} \mathrm{~s}^{-1}$ & $520 \mathrm{~L} \mathrm{~s}^{-1}$ \\
\hline Time constant & $20 \mathrm{~ms}$ & $20 \mathrm{~ms}$ \\
\hline $\begin{array}{l}\text { Minimum attainable } \\
\text { pressure }\end{array}$ & $10^{-5} \mathrm{~Pa}$ & $10^{-5} \mathrm{~Pa}$ \\
\hline \multicolumn{3}{|l|}{ Heating system } \\
\hline$T_{\text {sample }}=k_{0} T_{\text {reactor }}$ & $k_{0}=0.93$ & $k_{0}=0.9$ \\
\hline Main power supply & $7 \mathrm{~V} / 3 \mathrm{~A}$ & $7 \mathrm{~V} / 3 \mathrm{~A}$ \\
\hline Tunning electrical field & $500 \mathrm{~V}$ & $550 \mathrm{~V}$ \\
\hline$T_{\text {sample }}^{\max }$ & $500{ }^{\circ} \mathrm{C}$ & $500{ }^{\circ} \mathrm{C}$ \\
\hline $\begin{array}{l}\text { Maximum oxygen } \\
\text { pressure }\end{array}$ & $10^{-3} \mathrm{~Pa}$ & $10^{-3} \mathrm{~Pa}$ \\
\hline \multicolumn{3}{|l|}{ MS analyser } \\
\hline Ionisation volume & $0.38 \mathrm{~L}$ & $0.38 \mathrm{~L}$ \\
\hline Pumping speed & $0.63 \mathrm{~L} \mathrm{~s}^{-1}$ & $0.63 \mathrm{~L} \mathrm{~s}^{-1}$ \\
\hline Time constant & $500 \mathrm{~ms}$ & $500 \mathrm{~ms}$ \\
\hline $\begin{array}{l}\text { Potential applied to the } \\
\text { filament }\end{array}$ & $800 \mathrm{~V}$ & $800 \mathrm{~V}$ \\
\hline Limit detection pressure & $10^{-3} \mathrm{~Pa}$ & $10^{-3} \mathrm{~Pa}$ \\
\hline$K_{O_{2}}^{0}$ & $4.6 \times 10^{-8} \mathrm{~A} \mathrm{~Pa}^{-1}$ & $4.6 \times 10^{-8} \mathrm{~A} \mathrm{~Pa}^{-1}$ \\
\hline$K_{C O}^{0}$ & - & $8 \times 10^{-8} \mathrm{~A} \mathrm{~Pa}^{-1}$ \\
\hline$K_{\mathrm{CO}_{2}}^{0}$ & - & $5 \times 10^{-8} \mathrm{~A} \mathrm{~Pa}^{-1}$ \\
\hline \multicolumn{3}{|l|}{ Reactant gas supply } \\
\hline $\begin{array}{l}\mathrm{O}_{2}(46) \text { Carbagas } \\
\text { certified }\end{array}$ & HV chamber & $\begin{array}{l}\text { Reactor (both } \\
\text { sides) }\end{array}$ \\
\hline $\begin{array}{l}\text { CO }(60) \text { Carbagas } \\
\text { certified }\end{array}$ & - & $\begin{array}{l}\text { Working } \\
\text { compartiment }\end{array}$ \\
\hline Electrochemical reactor & Single chamber & Dual chamber \\
\hline $\begin{array}{l}\text { Working compartment } \\
\text { volume }\end{array}$ & $7 \times 10^{-4} \mathrm{~L}$ & $7 \times 10^{-4} \mathrm{~L}$ \\
\hline $\begin{array}{l}\text { Reference compartment } \\
\text { volume }\end{array}$ & $5 \times 10^{-4} \mathrm{~L}$ & $5 \times 10^{-4} \mathrm{~L}$ \\
\hline Pumping speed & $0.64 \mathrm{~L} \mathrm{~s}^{-1}$ & $0.9 \mathrm{~L} \mathrm{~s}^{-1}$ \\
\hline Time constant & $1 \mathrm{~ms}$ & $0.8 \mathrm{~ms}$ \\
\hline Transfer efficiency & 0.093 & 0.069 \\
\hline $\begin{array}{l}\text { Applied/measured } \\
\text { potential }\end{array}$ & $\Delta U_{\mathrm{WR}}=\eta$ & $\Delta U_{\mathrm{WR}} \neq \eta$ \\
\hline
\end{tabular}

temperature gradient between each side of the sample. The sample was heated by the reactor which acts as a radiation heat source allowing to supply a homogeneous heating of the sample up to $500{ }^{\circ} \mathrm{C}$. Worth to mention that, by adding openings in the reactor, the reactor time constant is decreased as well as the performance of the heating. Important limitation of the heating system concerns the oxygen partial pressure in the HV chamber, which should be kept below $10^{-3} \mathrm{~Pa}$ to avoid oxidation of the tungsten filament, i.e. the break of the heat source. 
The two electrochemical reactors realized, single and dual chamber type, feature low-volume of reactants and very small time constants (about $1 \mathrm{~ms}$ ) allowing a fast sampling of the electrochemical products. Because of their microreactor structures, these two reactors presented small transfer efficiencies $(0.093$ for the single chamber type and 0.069 for the dual chamber type). It is worth to note that the transfer efficiency parameter can be easily improved by sealing some openings on the sides of the reactors. However, it would result in an increase of gas back mixing effect and larger reactor time constant because of the decrease of reactor pumping speed which is highly undesired.

\section{Conclusion}

A new probe device, coupling electrochemistry and mass spectroscopy techniques, is developed for the investigation of a solid electrochemical cell under high vacuum conditions (HV). Vacuum system, heating system, mass spectrometric equipment and electrochemical reactor constitute the solid electrochemical mass spectrometry (SEMS). Two configurations are proposed, single and dual chamber type reactors, for the investigation of both the electrochemical and electrocatalytical behavior of the Pt/YSZ system. At this molecular level, the fast detection response of the herein built solid electrochemical mass spectrometry (SEMS) device allowed to observe a persistent promoted activity of Pt/YSZ catalyst induced by a Faradaic electrochemical promotion of CO oxidation over Pt/YSZ catalyst. The coupling of the SEMS device and HV conditions shows a real potential in the field of EPOC fundamental research.

Acknowledgement Financial support from the Fonds National Suisse de la Recherche Scientifique is gratefully acknowledged.

\section{References}

1. Williams FJ, Palermo A, Tikhov MS, Lambert RM (2000) J Phys Chem B 104:615

2. Williams FJ, Palermo A, Tikhov MS, Lambert RM (2001) Surf Sci 482-485:177

3. Luerßen B, Janek J, Imbihl R (2001) Solid State Ionics 141142:701

4. Luerßen B, Gunther S, Marbach H, Kiskinova M, Janek J, Imbihl R (2000) Chem Phys Lett 316:331

5. Imbihl R, Janek J (2000) Solid State Ionics 136-137:699

6. Poppe J, Völkening S, Schaak A, Janek J, Imbihl R (2000) Phys Chem Chem Phys 1:5241

7. Janek J, Luerßen B, Imbihl R, Rohnke M (2000) Phys Chem Chem Phys 2:1935

8. Vayenas CG, Bebelis S, Pliangos C, Brosda S, Tsiplakides D (2001) Electrochemical activation of catalysis: promotion, electrochemical promotion, and metal-support interactions. Kluwer Academic/Plenum Publishers, New York

9. Neophytides SG, Vayenas CG (1995) J Phys Chem 99:17063

10. Katsaounis A, Nikopoulou Z, Verykios XE, Vayenas CG (2004) J Catal 222:192

11. Katsaounis A, Nikopoulou Z, Verykios XE, Vayenas CG (2004) J Catal 226:197

12. Anastasijevic NA, Baltruschat H, Heitbaum J (1989) J Electroanal Chem 272:89

13. Baltruschat H (2004) J Am Soc Mass Spec 15:1693

14. Jaccoud A, Foti G, Comninellis C (2006) Electrochim Acta 51:1264

15. Foti G, Jaccoud A, Falgairette C, Comninellis C (2009) J Electroceram 23:175

16. Jaccoud A, Falgairette C, Foti G, Comninellis C (2007) Electrochim Acta 52:7927

17. Falgairette C, Jaccoud A, Foti G, Comninellis C (2008) J Appl Electrochem 38:1075

18. Judai K, Abbet S, Woerz A, Roettgen M, Heiz U (2003) Int J Mass Spectrom 229:99

19. Valloton R (2009) Thesis $n^{\circ} 4365$, EPFL. http://library.epfl.ch/ theses/?nr=4365

20. Hoffman DM, Singh B, Thomas JH III (eds) (1998) Handbook of vacuum science and technology. Academic Press, New York

21. Foti G, Stankovic V, Bolzonella I, Comninellis C (2002) J Electroanal Chem 532:191

22. Falgairette C, Xia C, Li YD, Harbich W, Foti G, Comninellis C (2010) J App Electrochem. doi:10.1007/s10800-010-0160-4 